\title{
A Discussion on Sea Level Rise, Rate Ad Acceleration. Venice as a Case Study
}

Dario Camuffo ( $\nabla$ d.camuffo@isac.cnr.it)

National Research Council, Institute of Atmospheric Sciences and Climate, Padua, Italy

\section{Research Article}

Keywords: Sea level rise, rate of sea level rise, sea level acceleration, trend-forecast extrapolation, Venice

Posted Date: December 15th, 2021

DOI: https://doi.org/10.21203/rs.3.rs-1073418/v1

License: (9) This work is licensed under a Creative Commons Attribution 4.0 International License. Read Full License 


\section{A discussion on sea level rise, rate ad acceleration. Venice as a case study}

Author: Dario Camuffo

Affiliation: National Research Council of Italy, Institute of Atmospheric Sciences and Climate, Corso Stati Uniti 4, 35127 Padua, Italy

ORCID iD https://orcid.org/0000-0002-1087-5797

Corresponding author E-mail: $\underline{\text { d.camuffo@isac.cnr.it }}$

11 Keywords: Sea level rise; rate of sea level rise; sea level acceleration; trend-forecast extrapolation; 12 Venice 


\section{Introduction}

\subsection{Defining the problem}

The sea level rise and flooding of the coastal areas is one of the most critical challenges of this century. The literature reports a variety of studies concerning the sea level and its past and present acceleration, as well as future changes. It was expected that the radiative forcing and the related Global Warming should produce the same acceleration on all oceans and seas, except for local departures. However, the situation is complex: different acceleration values have been determined from individual records over different geographical locations and different periods, most of which with different duration (Church and White 2006, 2011; Jevrejeva et al. 2008, 2014; Woodworth et al. 2009; Kemp et al. 2011; Olivieri and Spada 2013; Long et al. 2014; Camuffo et al. 2017). All records have a limited duration and are affected by multidecadal oscillations and regional effects that mask the true behavior: the longer the record, the less the noise affects the signal. However, even with the longest records there is not shared consensus about a common acceleration. Spada et al. (2015) considered that the existence of non-linear sea-level rising trends is still debated, and current estimates of the secular acceleration are subject to ample uncertainties. In particular, in a polynomial sea level representation, local effects with linear trend, e.g. land subsidence, affect the first order term, but not the second order, that represents the acceleration. In general, quadratic equations are preferred because they are simple and easy to interpret (Baart et al. 2012) and in addition make the acceleration clear (Jevrejeva et al. 2014).

A key problem is how acceleration is defined. The acceleration derived from a quadratic polynomial is necessarily constant, as discussed later. However, it has been recognized that the acceleration could vary over time. Therefore, alternative methods have been devised, e.g. using variable windows and sliding the window year-by-year along the observation period (Jevrejeva et al. 2014). An exponential equation was proposed to represent the sea level trend for coastal management in Australia, but this caused a dispute between Parker et al. (2013) and Hunter (2014).

Basically, two different views are involved: who prefers to rely on some basic equations to follow the physical process; who prefers to rely on the statistical analysis, take a long-term record and determine from it the equations derived from a best-fit interpolation. The former assumes to know, and to have the control of the whole system; therefore, he/she makes a subjective choice imposing an equation, although well motivated on scientific grounds. The latter assumes that the system is very complex and our knowledge insufficient; therefore, he/she leaves the record free to choose its equation, i.e. the best fit of the dataset, relying on statistical interpolation tools. Results will show which approach has been most successful.

In Venice, an exceptionally long-term series has been obtained for the sea level over the 1350-2016 period, based on tide gauge record (1871-2016) and some independent proxies, i.e.: the levels of the green algae belt on the palaces reported in the paintings by Canaletto and Bellotto ( $18^{\text {th }}$ century) and comparing them with the present-day level (Camuffo and Sturaro 2003, 2004); sea stair free from algae in a painting by Veronese dated 1571 (Camuffo 2010); the submersion depth of the sea stairs of the palaces facing the Grand Canal going back up to 1350 (Camuffo et al. 2017); the written documentary sources since the $16^{\text {th }}$ century (Camuffo 2021). This long multiproxy series can be interpolated at the same level of confidence (i.e. $\mathrm{R}^{2}=96 \%$ ) with a quadratic and an exponential equation. However, even if both equations represent equally well the sea level, their first and second derivatives, that concern the rising rate and the acceleration, give different responses. This gives the opportunity to make a general discussion about the consequences that may derive from choosing an equation instead of the other one, although they are apparently equivalent to describe the sea level over the whole observation period.

\subsection{Basic mathematical definitions and difficulties met in oceanography}


In this section, a few basic formulae are listed. They are well known, but are helpful in the following discussions and reference will be made to them. In kinematics, for any given function that describes the positions that a point occupies as it moves through space $\mathrm{S}(\mathrm{t})$ over time $t$, the velocity $\mathrm{V}(t)$ is represented by the first-order derivative of $\mathrm{S}(t)$ with respect to time, and the acceleration $\mathrm{A}(t)$ by the second-order derivative, i.e.

$6 \quad V(t)=\frac{d s(t)}{d t}$

$A(t)=\frac{d^{2} S(t)}{d t^{2}}=\frac{d V(t)}{d t}$

The above applies to all physical systems and variables, including climate changes and sea level rise. In the following, the sea level (SL) will stand for $S(t)$; the rate at which sea level is rising (SLR) for $\mathrm{V}(\mathrm{t})$ and the acceleration of sea level (SLA) for $\mathrm{A}(\mathrm{t})$. If the equation of $\mathrm{SL}(\mathrm{t})$ is a polynomial of degree $N$, then SLR and SLA are represented by the following equations

$S L=\sum_{n}^{N} a_{n} t^{n}$

$S L R=\frac{d S L}{d t}=\sum_{n}^{N} n a_{n} t^{n-1}$

$S L A=\frac{d^{2} S L}{d t^{2}}=\frac{d S L R}{d t}=\sum_{n}^{N} n(n-1) a_{n} t^{n-2}$

where $n=0,1,2, \ldots N$. In the particular case $\operatorname{SL}(\mathrm{t})$ is a quadratic equation, i.e. $N=2$, the acceleration becomes very simple, i.e. SLA $=2 a_{2}$. The easy rule of thumb by which the acceleration is twice the quadratic coefficient $a_{2}$ constitutes the conventional method used by oceanographers to define the acceleration (Jevrejeva et al. 2014). However, the fact of restricting the use to quadratic equations only is a strong limitation imposed to the representation of sea level records, and to the forcing factors as well, as explained later.

The last basic formula listed here is the second law of motion that establishes a cause-effect relationship that links acceleration to force, i.e.

$F(t)=m \frac{d V(t)}{d t}=m A(t)$

where $m$ is a proportionality coefficient that characterizes the inertia of the physical system, e.g. the resistance that a body offers to a change in its speed upon the application of a force $F(t)$. In this context, $\mathrm{F}(\mathrm{t})$ represents the atmospheric forcing that causes the sea level to rise and $m$ the inertia of oceans to respond, i.e. the ratio between the atmospheric forcing and sea level acceleration. It is trivial that, if $\mathrm{F}(\mathrm{t})$ has constant value, $\mathrm{A}(\mathrm{t})$ too is constant, and if $\mathrm{F}(\mathrm{t})=0$, also $\mathrm{A}(\mathrm{t})=0$ and $\mathrm{V}(\mathrm{t})$ is constant.

Eq.(6) can be read from left to right, i.e.: knowing or hypothesizing a forcing factor it is possible to know the acceleration and predict the sea level. The acceleration is a physical variable that indicates if the system determining the sea level is stationary or is forced to change, and represents the bulk effect of the primary and secondary forcing factors, e.g. radiative forcing, thermal expansion of waters, continental ice melting etc. If the same equation is read on the opposite direction, long records of sea level may be used to assess the forcing over the recording period. The former approach is used in models to predict future scenarios; the latter for global climate analyses.

In classical mechanics, all the physical quantities in Eq.(6) are derived from the Newton's laws: they are well-defined, with simultaneous interactions, and can be followed over time instant by instant. As opposed, in the complex Earth system, the atmospheric forcing drives mechanisms with different inertia and time scales. Therefore, the system may be split in a number of components, i.e. $m \mathrm{~A}(\mathrm{t})$ may be expressed as sum $\sum m_{i} \mathrm{~A}_{i}(\mathrm{t})$ of individual components $m_{i} \mathrm{~A}_{i}(\mathrm{t})$, each with a particular inertia and time scale, e.g. thermal expansion of oceanic waters, melting of land-based glaciers. The risk of direct sea level observations is that the short-term components are easily detected, while the 
long-term may pass unobserved. For this complication, it has been suggested to use the term 'apparent acceleration' (Douglas 1992) to emphasize that it is a partial result.

The concept of dose explains that a certain physical quantity may be distributed at high intensity for a short time, or at low intensity over a long time. High intensities produce high signals and are easily detected; low intensities produce low signals that may be difficult to observe, or may be masked by noise. This constitutes a serious difficulty for the long-term effects.

All the above considerations explain why the acceleration in sea level rise is difficult to detect and even to define; a further difficulty is that very long and accurate records are needed. Long tide gauge records are too short to monitor effects on the long-term time scales. Long proxy records may help to extend back in time our knowledge but this does not mean that they can always ensure the required time coverage.

\subsection{Analytical prediction models versus trend-forecast extrapolations}

Models are based on the best-knowledge hypotheses about mechanisms, boundary conditions and estimation of the forcing factors. Several authors have calculated SL scenarios for 2100 with sophisticated models, obtaining different results. Garner et al. (2018) compiled a comprehensive database of global SL projections showing a wide scatter of values. Wide ranges may be explained considering that projections beyond 2050 remain highly uncertain (Jevrejeva et al. 2019).

However, the Earth system is complex, and its representation is based on equations, forcing factors, rates, accelerations and time responses not so clearly determined. There is who believes that predictive models are based on physical equations to the best of our (limited) knowledge, and the method is scientific, but the application is biased because it involves uncertainties and subjective or hardly known assumptions, e.g. the forcing factors assumed in the model. Another approach is to abandon the analytical treatment and introduce a different one, similarly to artificial intelligence and machine learning process. Machine learning was developed with the advent of computers for pattern classification and recognition, and to make predictions. The underlying idea is that a sufficiently long dataset includes the due information and statistical tools are able to extract the trend and extrapolate it. The trend extrapolation makes a simple projection of how a physical system is evolving, and will continue to evolve in the absence of specific interventions to stop or to change it. When the historical data are smooth, and follow some nonlinear patterns and curves, extrapolation may be better than time-series analysis (Glanz and Moon 2011).

Extrapolation is a trend-forecast because it assumes that the forecast will not differ too much from the trend, especially when this has been established on a sound dataset. This method is convenient when forcing factors are expected to persist, or when they are not clearly understood, or their evolution is unclear, and avoids personal interpretations. It assumes that recent and historical trends will continue, i.e. the past behavior is a good predictor of the future. The trend-forecast is realistic when: (i) forecasts are short-term, i.e., the projected period is short in proportion to the record duration; (ii) $\mathrm{R}^{2}$ is high, because $\mathrm{R}^{2}$ represents the percentage variation of the observed variable (e.g. RSL) that is explained by the reference variable (e.g. time).

\subsection{Aims of this paper}

The first aim is to discuss the mathematics and the physics behind the equations, and in particular to interpret the difference between the quadratic and the exponential equations representing the best-fit of the multiproxy series in Venice (Camuffo et al. 2017). 
The second aim is to calculate and discuss the rate and the acceleration of sea level rise. These are obtained as fist and second time-derivative of the best-fit equations, and are commented in general, as well as for the specific case of Venice.

The third aim concerns the trend-forecast extrapolation. It has been recognized that, if not assumed to be the best approach, it could at least be used as a reference (Baart et al. 2012), i.e. it may be used to verify how much a model departs from the evolution kept over the known period, as well as the influence of the forcing factors considered in a model. It is clear that both computational models and trend-forecast extrapolations are subject to criticisms and limitations. However, they constitute two complementary approaches and the long multiproxy series offers the possibility of making a comparison between them.

\section{The multiproxy series representing the sea level in Venice}

The multiproxy series of the observed sea level (SL) in Venice for the 1350-2016 period (Camuffo et al. 2017) has been interpolated with two best-fit equations, one quadratic and one exponential, i.e.:

$S L=0.00153 \mathrm{t}_{\mathrm{yr}}^{2}-3.3 t_{y r}+480$

$S L=-1866+67.5 \exp \left(0.00166 t_{y r}\right)$

where $t_{\mathrm{yr}}$ is the time in years of the common era, SL is expressed in $\mathrm{mm}$, and the zero level is referred to the year 2000 (Figure 1). Both equations have the same fraction of unexplained variance, i.e. the same Pearson determination coefficient $\mathrm{R}^{2}=0.96$. From the physical point of view, any equation (including the sea level over time) is uniquely determined by the set of observed data and the regression analysis. If more than one best-fit equation is obtained, the best approach can be recognized from the unexplained variance. As Eq.(7a) and Eq.(7b) are characterized by the same $\mathrm{R}^{2}$, any choice between them is subjective, but implies different consequences, as discussed later.

As both interpolations are equally reliable, their difference represents the uncertainty of this system. The difference between the two equations (dotted line in Figure 1) is almost constant from 1500 to 1860 (in this interval it is close to the average, i.e. $22 \mathrm{~mm}$ ) and increases at the lower end. It is trivial to say that the difference vanishes at the year 2000 because it has been imposed as starting point (i.e. the zero level). Over the forecast period, i.e. 2020-2100, the difference increases and will reach 41 $\mathrm{mm}$ in 2100 .

\section{The rate of sea level rise in Venice}

The rate of SL, SLR ( $\left.\mathrm{mm} \mathrm{yr}^{-1}\right)$ is obtained by calculating the time derivatives of Eq.(7a) and Eq.(7b), i.e.

$$
S L R=\frac{d S L}{d t_{y r}}=\left(0.0031 t_{y r}-3.3\right)
$$

$S L R=\frac{d S L}{d t_{y r}}=0.11205 \exp \left(0.00166 t_{y r}\right)$

where the former is linear, the latter remains exponential (Figure 2).

Over the whole 1350-2016 common period, Eq.(8a) and Eq.(8b) provide the same average, i.e. SLR $=1.9 \pm 0.1 \mathrm{~mm} \mathrm{yr}^{-1}$, but in general they differ for the current-year values, especially before 1500 and after 1900.

Both equations are time dependent, showing that the rising rate was increasing over time, but the two formulae, and their graphs, are different. The linear graph of Eq.(8a) responds to a scenario with constant forcing factors, or with a unique average value, or responds to an inertial system with very 
the linear equation (derived from the quadratic one) may be used with the average value of the forcing factors, but misses any time evolution. As opposed, the exponential graph of Eq.(8b) responds to a scenario with increasingly stronger forcing factors and is more convenient to follow the time evolution of the system.

The relative sea level rise can be expressed as the sum of two factors: (i) eustatism i.e. rising the global sea level for thermal expansion of waters, melting of ice sheets, movements of the ocean floor, sedimentation, etc.; (ii) local land subsidence (LLS) i.e. lowering of the basin bottom for tectonic motions, soil compaction etc. The inhabitants and the tide gauge perceive the sum of the two, but each component can be determined separately. In Figure 2, the relative SLR has been reported together with LLS and its uncertainty band. In the literature, LLS ranges between 0.9 and $1.4 \mathrm{~mm}$ $\mathrm{yr}^{-1}$, with median $1.15 \pm 0.25 \mathrm{~mm} \mathrm{yr}^{-1}$ (see citations in Camuffo 2021). In the early period of the Venice series, the rate of the relative sea level rise was close to the LLS value, which implies that the eustatic component was very small or even null. This suggests a stationary period around the $14^{\text {th }}$ century in which the global sea level remained unchanged, or even had a turning point around a minimum in level. To ascertain which of the two hypotheses is correct, or if this is a misleading effect due to a larger uncertainty near the lower border, it is necessary to find new proxies to extend back in time the dataset. The eustatic component continued to grow over time and equated LLS at the end of the $17^{\text {th }}$ century and will likely be twice it near the end of this century (see section 5).

The graph of SLR shows an impressive acceleration, and the palaces with their sea stairs on the canals witness this dramatic situation (Figure 3). In the middle of the seventeenth century, the sea water rose at the rate to submerge one step in a century (the rise of the step of the Venice stairs is $1 / 2$ foot, i.e. $17.4 \mathrm{~cm}$ ). Over this century, more than two steps will be submerged. This is the tangible impact derived from Figure 2.

\section{The acceleration of sea level rise in Venice}

The acceleration is represented by the second-order time derivatives of Eq.(7a) and Eq.(7b), i.e.

$S L A=\frac{d^{2} S L}{d t_{y r}^{2}}=\frac{d S L R}{d t_{y r}}=0.0031$

$S L A=\frac{d^{2} S L}{d t_{y r}^{2}}=\frac{d S L R}{d t_{y r}}=0.000186 \exp \left(0.00166 t_{y r}\right)$

The plots are reported in (Figure 4).

The quadratic equation of SL leads to a constant acceleration, SLA $=2 a_{2}=0.0031 \mathrm{~mm} \mathrm{yr}^{-2}$ as established in Eq.(5). As previously discussed for Eq.(6), this implies one of the three following assumptions. (i) The system is governed by constant forcing. However, it is hard to believe that the radiative forcing has been constant over the last seven centuries with the Mediaeval Climatic Optimum, the Little Ice Age and the present-day Global Warming. (ii) The system is highly inertial. However, this is not fully realistic because the melting of ice in Antarctica has a long-term response, while the thermal expansion of waters has short-term. (iii) The equation is based on average values, i.e. average acceleration and average forcing over the record period: this gives a crude, but consistent representation of the physical system, as explained below.

The exponential equation of SL leads to an acceleration exponentially growing over time and shows, year by year, the evolution of the system.

These two results, i.e. constant and exponential acceleration, are only apparently contradictory because the former i.e. SLA $=0.0031 \pm 0.0004 \mathrm{~mm} \mathrm{yr}^{-2}$, equals the average of the values of Eq.(9b) over the 1350-2016 common period. As commented for the rate, both equations give the same bulk result, but in different ways. Eq.(9a) gives a stationary representation of the average acceleration that corresponds to the average forcing. On the other hand, the exponential equation is analytical and 
provides the time evolution of a system subject to increasing forcing factors, that reacts with an increasing acceleration. The choice between the two equations depends on the type of solution required, i.e. stationary (i.e. average, constant over time), or dynamic (i.e. instantaneous, varying over time). A stationary representation may be useful to interpret changes over a long period, once the average forcing is known. A dynamic representation may be convenient to represent an evolution over time, or to make future projections.

The result in Figure 4 can be compared to the acceleration on the global scale by Spada et al. (2015) over the common period 1898-1975. With the help of statistical methods and meta-analysis they found a global sea-level acceleration of $0.0054 \pm 0.0027 \mathrm{~mm} \mathrm{year}^{-2}$. In the same period, the average SLA in Venice calculated with Eq.(9b) has been $0.0047 \pm 0.0004 \mathrm{~mm} \mathrm{yr}^{-2}$. The two values are in reasonable agreement between them.

\section{Trend-forecast extrapolation to 2100 and uncertainties}

The literature includes a series of projections to 2100 for Venice under the hypothesis of business-asusual (Ferla et al. 2006; Scarascia and Lionello 2013; Lionello et al. 2020; Zanchettin et al. 2020). However, all of these projections are based on the tide-gauge record, active since 1872. The reasons to perform another projection are: (i) to compare them with the novel equation and discuss some subtle differences in methods; (ii) to test the relevance of the dataset length, i.e. in scholarly projections the dataset starts from 1872, while the multiproxy series from 1350. The exponential Eq. (7b) calculated for the year 2100 gives $33.8 \mathrm{~cm}$ above the level in 2000, set to zero, while the parabolic Eq.(7a) gives $29.7 \mathrm{~cm}$ (Figure 1). A discussion is due to assess the uncertainty of these findings.

The first uncertainty facing the multiproxy series concerns the choice of the best-fit interpolation as both the equations, i.e. quadratic and exponential, have the same $\mathrm{R}^{2}=0.96$. It has been demonstrated (Section 2, Figure 1) that the difference between the two plots, i.e. the uncertainty deriving from this choice, is $22 \mathrm{~mm}$, but may grow and reach $40 \mathrm{~mm}$ at the 2100 extreme when the two interpolations depart between them. As it has been demonstrated that only the exponential equation is physically correct because it responds to an increasing radiative forcing while the quadratic representation with constant acceleration does not, the quadratic equation should be rejected and this first uncertainty drops.

The second uncertainty is in the trend extrapolation and the stability of the forcing conditions. In theory, the trend-forecast extrapolation should have no error bar because the method is a tautology: if one assumes that the system has no changes in forcing, it is stationary and its trend remains unchanged. Under this assumption, by expanding the time domain, the extrapolation overlaps the trend. The question is another: how much the extrapolation will depart from truth if forcing will change? This is a specious question, i.e. to estimate the error that will derive from a method, when it is used improperly, in contrast to the assumption of steady conditions.

At this point, it should be made clear that the aim of the trend-forecast extrapolation is not to forecast the future, but only to identify a threshold: i.e. the value that a physical system would attain in the absence of changes, i.e. business-as-usual. On this ground, if the sea level will exceed the projected threshold, it will be possible to know the excess in rise and to evaluate the related excess in forcing.

A strong point of this method is that the learning period on which the business-as-usual is based is extended to the whole dataset that includes a number of variables, i.e.: the response of the system from the onset of the Little Ice Age (LIA) to the present-day Global Warming; changes in radiative forcing including periods of intense volcanic eruptions; inertial responses on the short and medium term of various factors to which the sea level responds. 
However, in practice, the trend-forecast extrapolation is sometimes used for projections on the short or medium term, until changes remain negligible, i.e. when the forecast period (i.e. the future) is short compared to the duration of the learning period (i.e. the record of historical data). It could be argued that in every prediction the uncertainty will increase with the departure from the initial conditions, and ultimately with the length of the extrapolation period. This condition may be expressed in term of relative future, i.e. the ratio between the forecast period, and the learning period. In the case of the multiproxy series in Venice, the forecast period is constituted by 83 years from 2017 to 2100, and the length of the multiproxy record is $2016-1350=666$ years. The relative future is $83 / 666=12 \%$ of the record duration. On this ground, one might assume that the uncertainty is of the order of $12 \%$ of the $33.8 \mathrm{~cm}$ forecast, i.e. $33.8 \pm 4 \mathrm{~cm}$, by considering only the exponential projection. This result may be compared with other similar findings.

The Venice Agency for the Protection of the Environment and Technical Services (APAT) made a simple projection to 2100 by extrapolating the best-fit of the 1872-2005 tide-gauge record using three equations: exponential, parabolic and linear. The respective projections are: $31.3 \mathrm{~cm}, 25.3 \mathrm{~cm}$ and $26.6 \mathrm{~cm}$ (Ferla et al. 2006) without indication of the uncertainty. The record is long 133 years; and the extrapolated period, from 2006 to 2100 , is $70 \%$ of the record length. Operating as before, the uncertainty is $70 \%$ of the forecasted values. Therefore, if one compares the APAT extrapolation with this work, by considering only the exponential equation and excluding the quadratic or the linear approximations because physically incorrect, one obtains similar projections but different uncertainty i.e. $31.3 \pm 18 \mathrm{~cm}$ (APAT) versus $33.8 \pm 4 \mathrm{~cm}$ (this paper).

Scarascia and Lionello (2013) also using the tide-gauge record under the A1B emission scenario, repeated the APAT forecast with an exponential, parabolic and linear equation, and predicted $43.5 \pm$ $5 \mathrm{~cm}, 18 \pm 6 \mathrm{~cm}$ and $27 \pm 5 \mathrm{~cm}$ respectively. These findings are very different between them, and the exponential, gives a projection (i.e. $43.5 \pm 5 \mathrm{~cm}$ ) higher than this work, while the quadratic (i.e. $18 \pm$ $6 \mathrm{~cm}$ ) lower.

Recently, Lionello et al. (2020) and Zanchettin et al. (2020) returned on the topic and proposed a broader projection range, between 11 and $110 \mathrm{~cm}$, in line with the $31-110 \mathrm{~cm}$ of the IPCC prediction under the business-as-usual scenario (Warrick et al. 1990)

The exponential extrapolation of this paper (i.e. $33.8 \pm 4 \mathrm{~cm}$ ) is similar to APAT (i.e. $31.3 \pm 18 \mathrm{~cm}$ ), and to the lower limit of the IPCC prediction (i.e. $31 \mathrm{~cm}$ ), but is lower than the prediction (i.e. $43.5 \pm$ $5 \mathrm{~cm}$ ) by Scarascia and Lionello (2013) and higher than the lower than the $11 \mathrm{~cm}$ threshold by Lionello et al. (2020) and Zanchettin et al. (2020).

\section{Conclusions}

Although quadratic equations are popularly preferred to represent the sea level for their easy interpretation and the explicit acceleration value (Baart et al. 2012, Jevrejeva et al. 2014) it is not said that they constitute the best choice. This paper has demonstrated that, when a quadratic polynomial is used to represent the sea level, the acceleration is necessarily constant, which implies a constant forcing. Constant forcing is typical of the physical situation in the middle of a homogeneous climatic age, but can hardly represent the transition period form a climatic age to another, e.g. from LIA to Global Warming and especially nowadays in view of the IPCC emission scenarios. An increasing radiative forcing requires an increasing acceleration, e.g. sea level represented with an exponential or a polynomial of order higher than 2 .

Climate forcing may drive different mechanisms that will affect the sea level, each of them characterized by a different response time and related acceleration. Effects with short response time have more probability of being observed, and will be better monitored, than mechanisms with long response. This constitutes a serious difficulty for analytical equations. 
When the sea level is represented with quadratic equations, their derivatives generate constant values These can be interpreted in terms of average values of rates, or accelerations, over relatively short periods, in which the selected physical variable does not change too much. As already noted (Camuffo et al. 2017), in every record, every selected period is characterized by a different acceleration rate. It was noted that the acceleration may change from a period to another (Jevrejeva et al. 2014). The casestudy of Venice gives an excellent example of acceleration continually increasing over time that fits with a continuous warming from LIA to nowadays. Therefore, in order to make comparable scholarly results concerning different geographical locations, it is necessary to consider accelerations over a common reference period, the same for all records. By comparing the acceleration of the multiproxy series in Venice to the acceleration on the global scale by Spada et al. (2015) over the common period $1898-1975$, the two values are respectively $0.0047 \pm 0.0004 \mathrm{~mm} \mathrm{yr}^{-2}$ and $0.0054 \pm 0.0027 \mathrm{~mm}$ year $^{-2}$, in reasonable agreement between them.

The case-study of Venice has shown that a (long) dataset may be represented with more than one best-fit equation. Although the choice of the equation may be irrelevant to determine the average sea level of the current year, either in the past, or in future projections, the choice may become highly relevant when dealing with the formulae of rising rate and acceleration.

By calculating the first, and the second time-derivatives of the best-fit equations of the sea level in Venice, one obtains two equations for both the rising rate and the acceleration. These equations give the same average results, but one of them presents a scenario in which the forcing factor is constant, and the other is exponentially growing over time. The former gives a stationary response (i.e. constant over time), the latter a dynamical one (i.e. variable over time). The choice depends on the aims (e.g. bulk average representation and characterization of a climate period; the need of instantaneous data or future projections) and the physical assumptions about the involved scenario. In general, the exponential is preferable because it is subject to less limitations.

It has been explained that the trend-forecast extrapolation cannot be used to forecast the sea level, but may be used to determine the lower threshold that may be reached by the end of this century. This constitutes the most favorable scenario if the radiative forcing will continue to keep the trend included in the dataset, i.e. the for business-as-usual, where the term "usual" means the trend and the increasing forcing over the multiproxy dataset. It must be specified that the Venice dataset has the exceptional duration of over 6.5 centuries, from LIA to nowadays. Therefore, it includes a radiative forcing with increasing trend (not a constant one), in analogy with the present-day warming. Under these assumptions, the projected scenario is $33.8 \pm 4 \mathrm{~cm}$ rise over this century. This result is consistent with the exponential extrapolation by APAT (Ferla et al. 2006), i.e. $31.3 \mathrm{~cm}$ that we estimate with $\pm 18 \mathrm{~cm}$ uncertainty due to the shorter duration. It is also consistent with the lower limit of the IPCC prediction made with analytical models, i.e. $31-110 \mathrm{~cm}$ under the business-as-usual scenario (Warrick et al. 1990). However, it is lower than the exponential projection $43.5 \pm 5 \mathrm{~cm}$ by Scarascia and Lionello (2013), and higher than the recent $11 \mathrm{~cm}$ threshold revisited by Lionello et al. (2020) and Zanchettin et al. (2020). It must be specified that Ferla et al. (2006), Scarascia and Lionello (2013), Lionello et al. (2020) and Zanchettin et al. (2020) rely on the shorter tide-gauge dataset and business-as-usual.

In Venice, the relative sea level followed a continually rising trend since 1350, when the multiproxy documentation starts. The observed data do not support a minimum level around the early $18^{\text {th }}$ or $19^{\text {th }}$ century as suggested by Vermeer and Rahmstorf (2009), Grinsted et al. (2010) and Kemp et al. 2011. This suggestion might respond to a theoretical consideration that, for the cooling that culminated in the middle of LIA, the oceanic waters should have increased their density and contracted their volume, reaching a minimum level, but this trend has not been observed. A stasis, or even a turning point around a minimum of the eustatic component could have been possible in the early period of the multiproxy series (i.e. the $14^{\text {th }}$ century). After, the eustatic component continued to grow over time. Starting from the $19^{\text {th }}$ century, it became dominant over LLS, and near the end of this century, it will likely exceed twice the LLS rate. 


\section{References}

Baart F, van Koningsveld M, Stive MJF (2012) Trends in Sea-Level Trend Analysis. J Coast Res 28(2):311-315. DOI: 10.2112/JCOASTRES-11A-00024.1

Camuffo D (2010) Le niveau de la mer à Venise d'après l'œuvre picturale de Véronèse, Canaletto et Bellotto. Révue d'Histoire Moderne et Contemporaine, 57(3):92-110. DOI: $0.3917 /$ rhmc.573.0092

Camuffo D (2021) Four centuries of documentary sources concerning the sea level rise in Venice. Climatic Change (in press). DOI: 10.1007/s10584-021-03196-9

Camuffo D, Sturaro G (2003) Sixty-cm submersion of Venice discovered thanks to Canaletto's paintings. Climatic Change, 58:333-343. DOI: 10.1023/A:1023902120717

Camuffo D, Sturaro G (2004) Use of proxy-documentary and instrumental data to assess the risk factors leading to sea flooding in Venice, Global and Planetary Change, 40:93-103. DOI: 10.1016/S0921-8181(03)00100-0

Camuffo D, Bertolin C, Schenal P (2017) A novel Proxy and SLR in Venice, Italy, from 1350 to 2014. Clim Chang 143(1):73-86. DOI: 10.1007/s10584-017-1991-3

Church JA, White NJ (2006) A 20th century acceleration in global sea-level rise. Geophys Res Lett 33:L10602. DOI: 10.1029/2005GL024826

18 Church JA, White NJ (2011) Sea-Level Rise from the Late 19th to the Early 21st Century. Surv Geophys 32:585-602. DOI: 10.1007/s10712-011-9119-1

Douglas B (1992) Global sea level acceleration. J Geophys Res 97(C8):12,699-12,706. DOI: 10.1029/92JC01133

Ferla M, Cordella M, Michielli L (2006) Aggiornamenti sulle osservazioni dei livelli di marea a Venezia. Report 69/2006 APAT, Rome

Garner AJ, Weiss JL, Parris A, Kopp RE, Horton RM, Overpeck JT, Horton BP (2018) Evolution of 21st Century SLR Projections. Earth's Future 6(11):1603-1615. DOI: 10.1029/2018EF000991

Glanz M, Moon J (2011) Credit Engineering for Bankers, Academic Press, New York

Grinsted A, Moore JC, Jevrejeva S (2010) Reconstructing sea level from paleo and projected temperatures 200 to 2100 AD. Clim Dynam 34:461-472. DOI:10.1007/s00382-008-0507-2

Jevrejeva S, Moore JC, Grinsted A, Matthews AP, Spada G (2014) Trends and acceleration in global 10.1016/j.gloplacha.2013.12.004

Jevrejeva S, Moore JC, Grinsted A, Woodworth PL (2008) Recent global sea level acceleration started over 200 years ago? Geophys Res Lett 35:L08715. DOI: 10.1029/2008GL033611

Jevrejeva S, Frederikse T, Kopp RE, Le Cozannet G, Jackson LP, van de Wal RSW (2019) Probabilistic Sea Level Projections at the Coast by 2100. Surv Geophys 40:1673-1696. DOI: 10.1007/s10712-019-09550-y

Hunter J (2014) Comment on 'sea-level trend analysis for coastal management' by A. Parker, M. Saad Saleem and M. Lawson. Ocean Coast Manag 87:114-115. DOI: 10.1016/j.ocecoaman.2013.10.023

Kemp AC, Horton BP, Donnelly JD, Mann ME, Vermeer M, Rahmstorf S (2011) Climate related sea-level variations over the past two millennia. Proc National Academy of Tufts University Sciences 108(27):11017-11022. DOI: 10.1073/pnas.1015619108 
Lionello P, Nicholls RJ, Umgiesser G, Zanchettin D (2020) Introduction to the special issue "Venice flooding and sea level: past evolution, present issues and future projections". Nat. Hazards Earth Syst. Sci. Discuss. [preprint], DOI: 10.5194/nhess-2020-367 (in press)

Long AJ, Barlow NLM, Gehrels WR, Saher MH, Woodworth PL, Scaife RG (2014) Contrasting records of sea-level change in the eastern and western North Atlantic during the last 300 years. Earth Planet Sci Lett 388:110-122. DOI: 10.1016/j.epsl.2013.11.012

Olivieri M, Spada G (2013) Intermittent sea level acceleration. Glob Planet Chang 109:64-72. DOI: 10.1016/j.gloplacha.2013.08.004

Parker A, Saleem MS, Lawson M (2013) Sea-level trend analysis for coastal management. Ocean 10 Coast Manag 73:63-81. DOI: 10.1016/j.ocecoaman.2012.12.005

11 Scarascia L, Lionello P (2013) Global and regional factors contributing to the past and future sea level rise in the Northern Adriatic Sea. Glob Planet Change 106:51-63. DOI: 10.1016/j.gloplacha.2013.03.004

Spada G, Olivieri M, Galassi G (2015) A heuristic evaluation of long-term global sea level acceleration. Geophys Res Lett 42:4166-4172. DOI: 10.1002/2015GL063837

Vermeer M, Rahmstorf S (2009) Global sea level linked to global temperature PNAS 106(51): 2152721532. DOI: 10.1073/pnas.0907765106

Warrick RA, Oerlemans J, Beaumont P, Braithwaite RJ, Drewry DJ, Gornitz V, Grove JM, Haeberli W, Higashi A, Leiva JC, Lingle CS, Lorius C, Raper SCB, Wold B, Woodworth P L (1990) Sea level rise. Climate change: The IPCC Scientific Assessment. Cambridge University Press, Cambridge, p. 257-282. https://www.ipcc.ch/report/ar1/wg1/sea-level-rise/

Woodworth PL, White NJ, Jevrejeva S, Holgate SJ, Church JA, Gehrels WR (2009) Evidence for the accelerations of sea level on multidecade and century time scales. Int J Climatol 29:777-789. DOI: 10.1002/joc. 1771

Zanchettin D, Bruni S, Raicich F, Lionello P, Adloff F, Androsov A, Antonioli F, Artale V, Carminati E, Ferrarin C, Fofonova V, Nicholls RJ, Rubinetti S, Rubino A, Sannino G, Spada G, Thiéblemont R, Tsimplis M, Umgiesser G, Vignudelli S, Wöppelmann G, Zerbini S (2020) Review article: Sealevel rise in Venice: historic and future trends, Nat. Hazards Earth Syst. Sci. Discuss. [preprint], DOI: 10.5194/nhess-2020-351

32 Data availability: Not applicable.

33 Code availability: Not applicable.

34 Declarations

35 Funding: Not applicable.

36 Conflict of interest: The author declares no competing interests. 
3 Figure 1. Plots of the multiproxy series of sea level in Venice. Dashed line: quadratic interpolation 4 (Eq.7a); continuous line: exponential interpolation (Eq.7b); dotted line: difference between the quadratic and the exponential interpolation. Grey area: extrapolated values.

Figure 2. Rate of relative sea level rise and rate of LLS in Venice. Dashed line: linear interpolation (Eq.8a); continuous line: exponential interpolation (Eq.8b). Horizontal lines: LLS (continuous central value: $1.15 \mathrm{~mm} \mathrm{yr}^{-1}$; lower and upper dashed limits: 0.9 and $1.4 \mathrm{~mm} \mathrm{yr}^{-1}$ ). Grey area: extrapolated values.

Figure 3. At high tides, this sea stair is fully submerged. All steps are colonized by algae and shells. Nowadays this stair is totally impractical. The upper front of green algae is the level currently reached by sea water (normal tides and small waves). Picture taken at low tide.

Figure 4. Acceleration of sea level rise in Venice. Dashed line: constant acceleration (Eq.9a); continuous line: exponential acceleration (Eq.9b). Left scale: International System of Units ( $\mathrm{mm} \mathrm{yr}^{-}$ ${ }^{2}$ ); right scale: myc unit $\left(\mathrm{mm} \mathrm{yr}^{-1}\right.$ century $\left.^{-1}\right)$ popularly used in oceanography. Grey area: extrapolated values. 


\section{Figures}

\section{Figure 1}

Plots of the multiproxy series of sea level in Venice. Dashed line: quadratic interpolation (Eq.7a); continuous line: exponential interpolation (Eq.7b); dotted line: difference between the quadratic and the exponential interpolation. Grey area: extrapolated values.

\section{Figure 2}

Rate of relative sea level rise and rate of LLS in Venice. Dashed line: linear interpolation (Eq.8a); continuous line: exponential interpolation (Eq.8b). Horizontal lines: LLS (continuous central value: 1.15 mm yr-1; lower and upper dashed limits: 0.9 and $1.4 \mathrm{~mm}$ yr-1). Grey area: extrapolated values. 


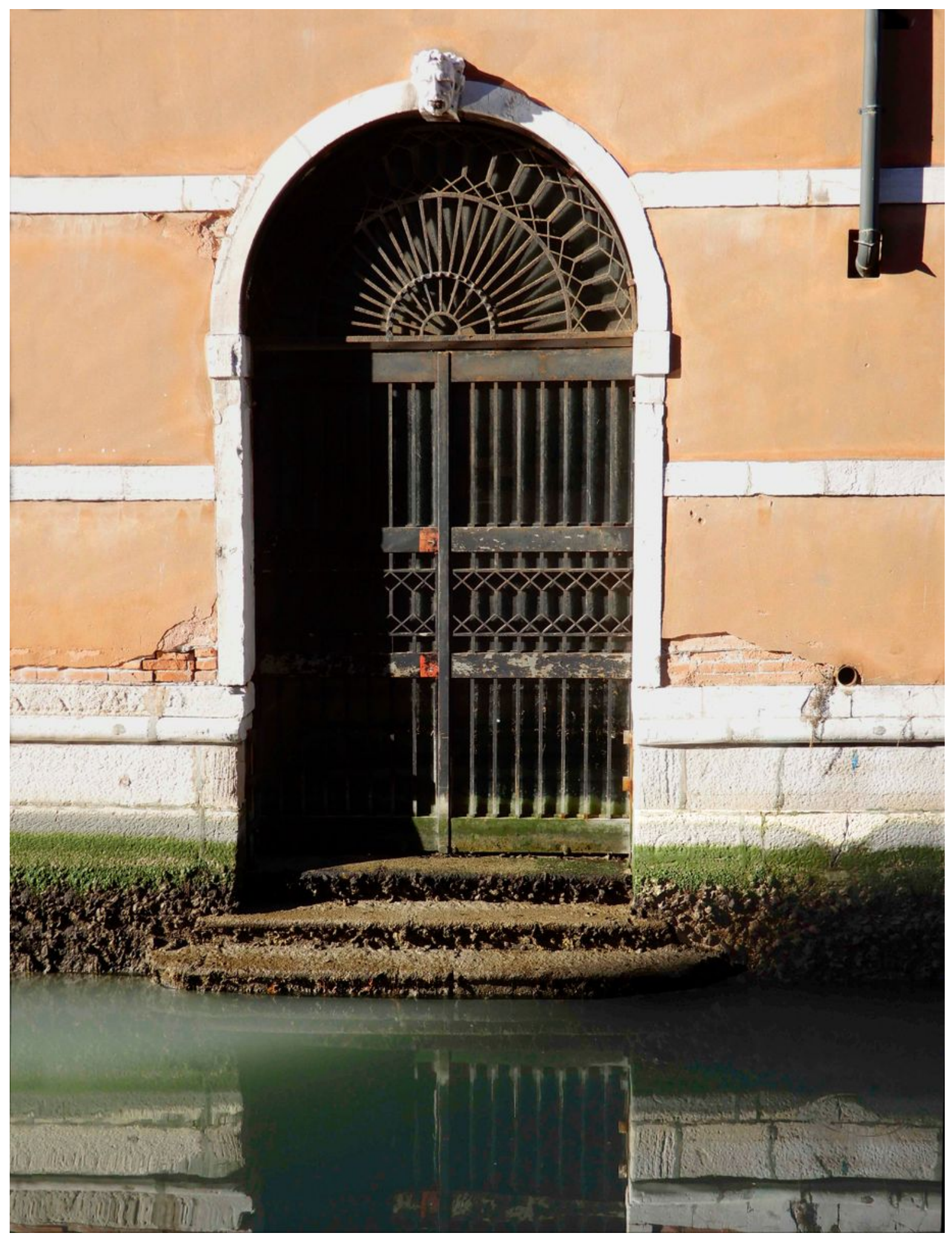

Figure 3

At high tides, this sea stair is fully submerged. All steps are colonized by algae and shells. Nowadays this stair is totally impractical. The upper front of green algae is the level currently reached by sea water (normal tides and small waves). Picture taken at low tide. 


\section{Figure 4}

Acceleration of sea level rise in Venice. Dashed line: constant acceleration (Eq.9a); continuous line: exponential acceleration (Eq.9b). Left scale: International System of Units ( $\mathrm{mm}$ yr-2); right scale: myc unit ( $\mathrm{mm}$ yr-1 century-1) popularly used in oceanography. Grey area: extrapolated values. 